\title{
Immunohistochemical localization of secretory component and immunoglobulin $A$ in the urogenital tract of the male rodent
}

\author{
M. B. Parr and E. L. Parr \\ Southern Illinois University, School of Medicine, Department of Anatomy, Carbondale, IL 62901, \\ U.S.A.
}

\begin{abstract}
Summary. The mucosal immune system in the male rodent urogenital tract was studied by localizing secretory component (sc) in the rat and immunoglobulin $\mathrm{A}(\operatorname{IgA})$ in both rat and mouse by immunofluorescence. In the rat, bright labelling of sc was observed at several sites, including the ejaculatory ducts, excretory ducts of several accessory glands, and urethral glands in the pelvic and bulbous portions of the urethra. Pale labelling of sc was detected in epithelial cells of the ventral prostate gland. Plasma cells containing $\operatorname{IgA}$ were only observed in the urethral gland in the bulbous portion of the urethra in rats and mice. These results suggest that IgA may be transported into the urogenital tract of the male rat primarily at sites distal to the production of seminal fluid and spermatozoa. While locally synthesized IgA may be available in the bulbous urethra, it appears that serum may be the main source of IgA for transport into the rat urogenital tract at the other sites where its receptor, sc, was demonstrated.
\end{abstract}

Keywords: secretory component; mucosal immunity; immunoglobulin A; male urogenital tract; rat

\section{Introduction}

The occurrence and possible functions of a mucosal immune system in the male urogenital tract are not well understood and have thus far been studied mainly in man. Immunoglobulins A (IgA) and $\mathrm{G}$ (IgG) have been detected in the seminal fluids of normal men (Chodirker \& Tomasi, 1963; Herrmann \& Hermann, 1969; Uehling, 1971; Rumke, 1974; Tauber et al., 1975), secretory IgA (sIgA) with anti-sperm activity has been found in the genital tracts of some men after vasectomy (Witkin et al., 1983), and IgA or sIgA sperm agglutinins have been reported in the seminal plasma of men with autoimmunity to spermatozoa (Friberg, 1974; Husted \& Hjort, 1975; Witkin et al., 1981; Bronson et al., 1984). While these studies indicate that secretory immunoglobulins are present in seminal fluid, little is known about their origin. Prostatic fluids contain IgA (Chodirker \& Tomasi, 1963), and studies of split human ejaculates have suggested that seminal fluid immunoglobulins may originate either in the prostate (Rumke, 1974; Hekman \& Rumke, 1976) or in the seminal vesicles (Uehling, 1971). Using an immunofluorescence technique, Ablin et al. (1972) reported that the human prostate contained a few IgA plasma cells, IgG in the basal part of the epithelial cells, and both $\operatorname{IgA}$ and $\operatorname{IgG}$ in secretory granules in the lumen of the prostatic ducts. Their studies suggested that secretory epithelial cells in the prostate may be involved in the accumulation and discharge of immunoglobulins.

There is no information available regarding the production of $\operatorname{sgA}$ in male genital tracts of other animals. In particular, such information is needed in laboratory rodents in preparation for experimental studies that will help to define the role of mucosal immunity in the male urogenital tract. In the present study we have used an immunofluorescence technique to localize sc and $\operatorname{IgA}$ in the rat male genital tract and $\operatorname{IgA}$ in the mouse tract. 

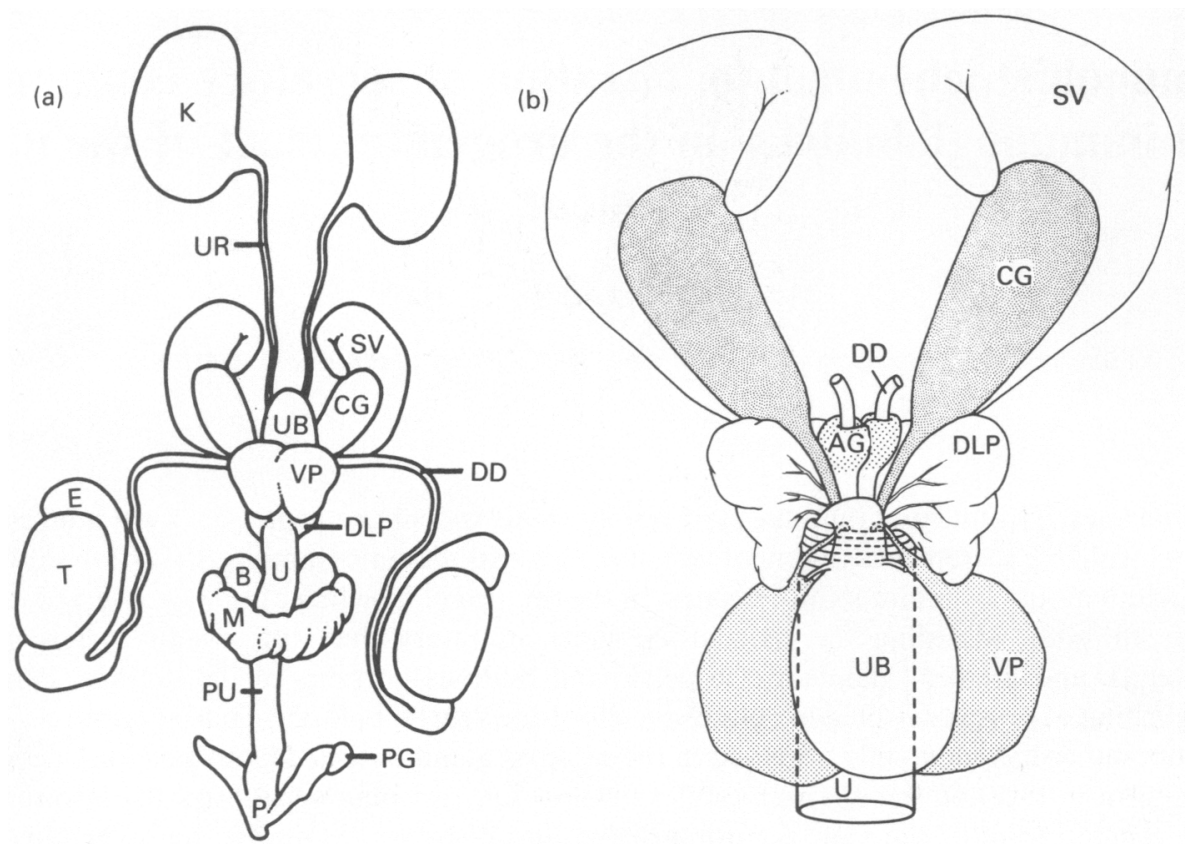

Fig. 1. Diagrams of the ventral view of the rat urogenital tract, (a) undisturbed and (b) with the ventral prostate glands and urinary bladder deflected forward and down. K, kidney; UR, ureter; UB, urinary bladder; U, pelvic urethra; PU, penile urethra; T, testis; E, epididymis; DD, ductus deferens; SV, seminal vesicle; CG, coagulating gland; VP, ventral prostate gland; DLP, dorsolateral prostate gland; B, bulbourethral gland; $\mathbf{M}$, bulbocavernous muscle (Hebel \& Stromberg, 1986); P, penis; PG, preputial gland. In (b) the morphological relationships of the accessory gland ducts, ductus deferens, ampullary gland (AG), and urethra just before their entrance into the glandular pelvic urethra are shown.

\section{Materials and Methods}

Sprague-Dawley male rats (Harlan, Sprague-Dawley, Inc., Indianapolis, IN, USA) 3-6 months old, and ICR male mice (Sasco, Inc., Omaha, NE, USA) 2-4 months old were used. The entire reproductive tract, duodenum, kidney, and urinary bladder were removed from 9 rats, cut into smaller segments and fixed by immersion in $2 \%$ acetic acid$10 \%$ formalin in isotonic saline $\left(4^{\circ} \mathrm{C}\right)$ for approximately $6 \mathrm{~h}$. The fixed tissues were processed and labelled to demonstrate IgA and sc as described previously (Parr \& Parr, 1989). The genital tracts of 6 additional rats were used for morphological and histological studies. Ten mice were used for localization of IgA. Histological sections of the mouse tissues were prepared as described above and incubated in the following reagents at room temperature with intermediate washings in PBS: $2 \%$ normal rabbit serum for $30 \mathrm{~min}$; $1 / 50$ dilution of rhodamine-labelled rabbit anti-mouse IgA ( $\alpha$ chain specific, Zymed Laboratories, Inc., San Francisco, CA, USA) for $1 \mathrm{~h}$. Specificity of the antibody was demonstrated by an inhibition of labelling when the antibody was combined with an excess of purified myeloma IgA (MOPC-315, Walgene R and D, Arcadia, CA, USA). Positive controls were obtained by labelling IgA plasma cells in the duodenum. All histological sections were mounted with polyvinyl alcohol and examined using an Olympus microscope equipped with epifluorescence. From each animal 5-10 sections from each region were examined for IgA or sc labelling.

\section{Results}

\section{Morphology of the male rat urogenital tract}

Two regions of the rat genital tract are of particular interest in this study: the ducts of the accessory glands as they enter the proximal part of the glandular pelvic urethra and the urethral 


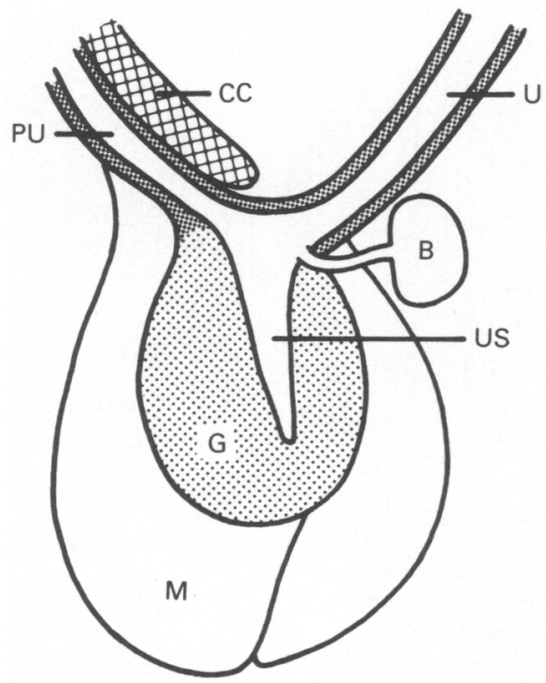

Fig. 2. This diagram is of a sagittal section through the pelvic (U) and penile urethrae (PU) and shows the diverticulum or urethral sinus (US) and the urethral gland (G) in the wall of the bulbous portion of the urethra surrounded by muscle $(M)$. The bulbourethral gland $(B)$ empties into the urethral sinus. CC, corpus cavernosum.
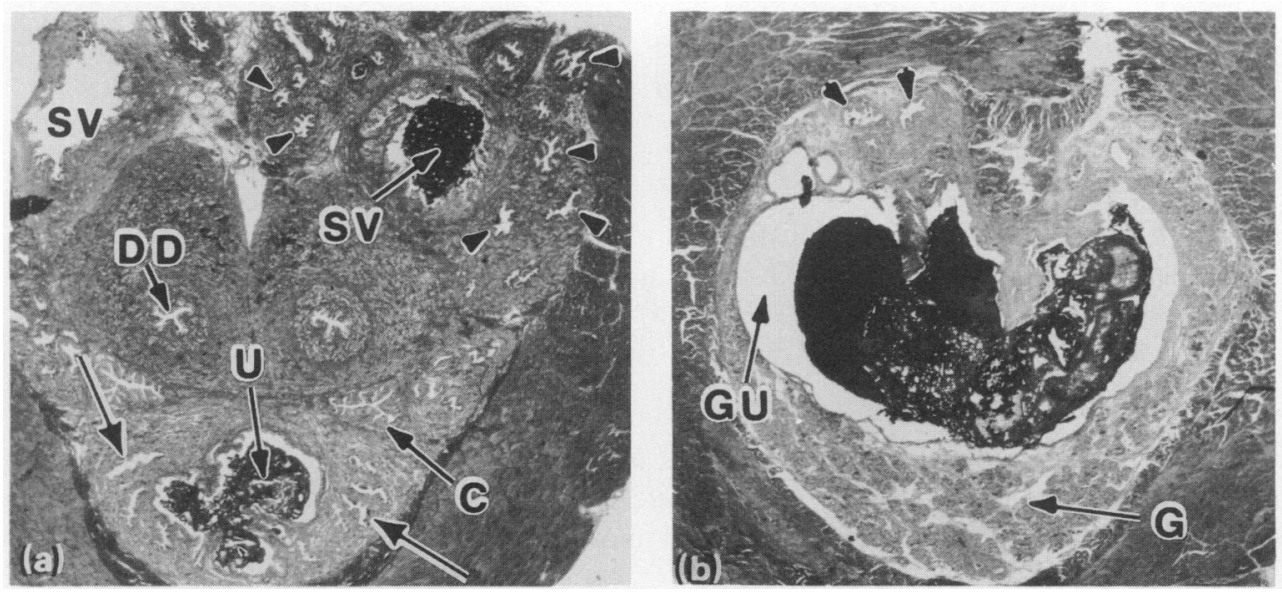

Fig. 3. Histological cross-sections of the glandular pelvic urethra (a, cranial to the proximal part; $\mathbf{b}$, distal to that of a) showing the urethra (U), ductus deferens (DD), and ducts of the coagulating $(\mathrm{C})$, ventral prostate (arrows), dorsolateral prostate (arrowheads), and seminal vesicle (SV) glands. In (b), the urethral gland (G) can be seen in the cavernosus layer of the wall of the urethra under the epithelium. Several ducts of the dorsolateral prostate glands (arrowheads) are present. The urethra, ejaculatory ducts $(G U)$ and all the excretory ducts of the accessory glands open into this common urethral chamber. $\times 10$.

gland in the bulb of the penis. Because the morphology of these regions is not commonly known, we present a brief description of their structure (for additional information see Hall, 1936; Levy \& Fair, 1973; Hebel \& Stromberg, 1986).

The accessory glands include the ampullary glands (glands of the ductus deferens), prostate glands and seminal vesicles (Fig. 1). Each ampullary gland surrounds the terminal part of the 

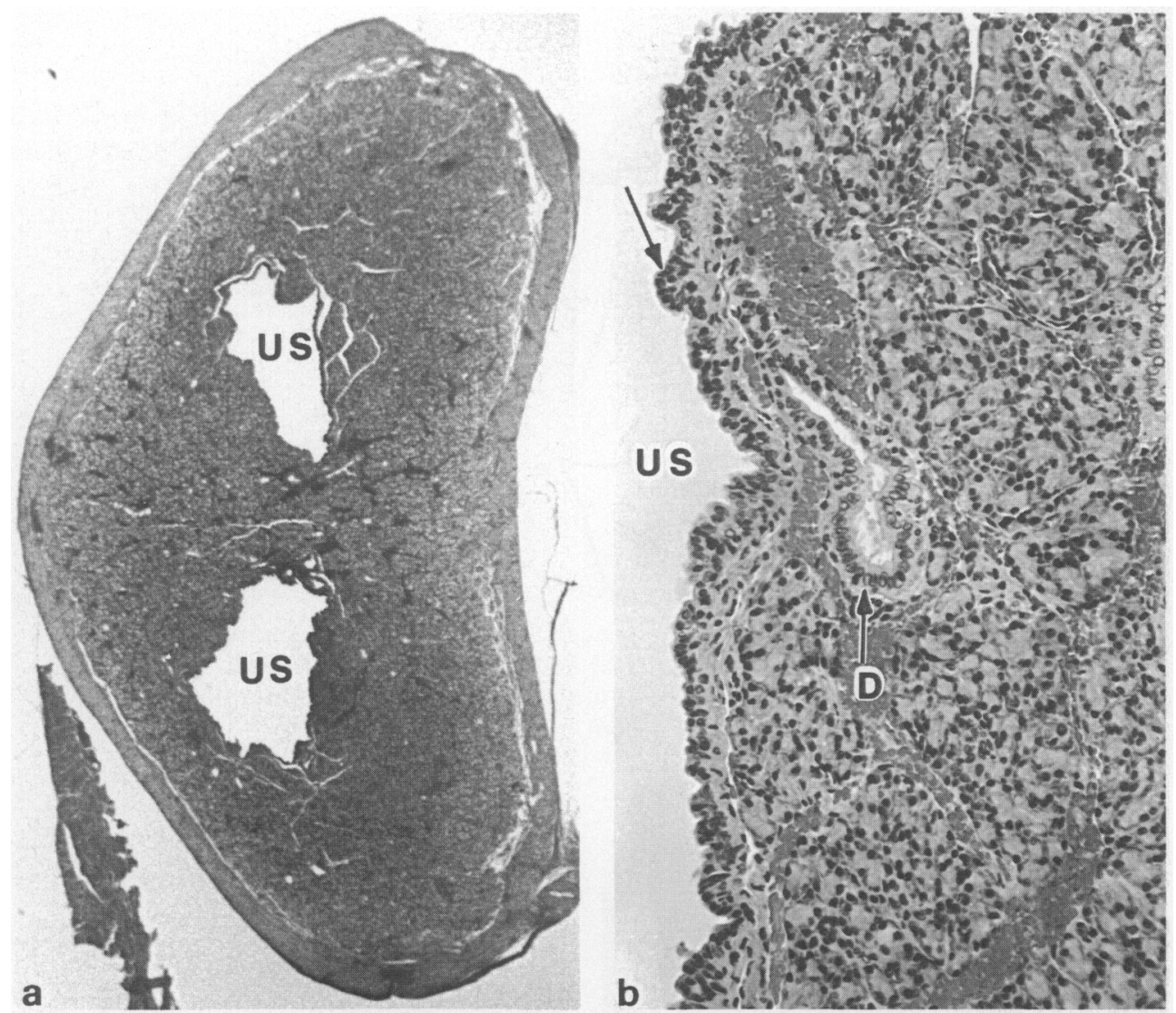

Fig. 4. Histological cross-section of the bulb of the penis showing the two chambers of the urethral sinus (US) which bifurcated from the main chamber and the large amount of urethral gland tissue, including acini and ducts (D), in the cavernosus layer under the lining epithelium (arrow). a, $\times 15 ; \mathrm{b}, \times 220$.

ductus deferens and both the ampullary gland and the ductus deferens empty into a common chamber called the ampulla. The prostate gland consists of 3 pairs of lobes: anterior, ventral and dorsolateral. The anterior lobes are also referred to as the coagulating glands. The ventral lobes are attached to the ventrolateral side of the urinary bladder and superficially appear to be drained by a single pair of ducts situated at the lateral aspect of the urethra. However, on closer inspection each duct consists of approximately 4 small ducts. The dorsolateral lobes of the prostate gland encircle the excretory ducts of the seminal vesicles, coagulating glands, and ductus deferens. Each dorsolateral prostate lobe is drained by collecting ducts that unite to form about 22 excretory ducts. The coagulating glands are situated on the concave side of the seminal vesicles and empty by a pair of long tapered excretory ducts situated lateral and ventral to the ductus deferens. The large pair of excretory ducts of the seminal vesicles are located dorsal to the ductus deferens and each empties into the terminal part of the ampulla to form a short common duct (ejaculatory duct) which opens into the glandular urethra. All the other ducts of the accessory glands run more or less parallel to one another and empty directly into the glandular urethra. The short non-glandular urethra extending from the urinary bladder also opens into the proximal part of the glandular urethra. The cavernous layer of the glandular urethra contains acini of the urethral gland that open independently into the lumen by means of short ducts. Thus, the proximal part of the glandular pelvic 

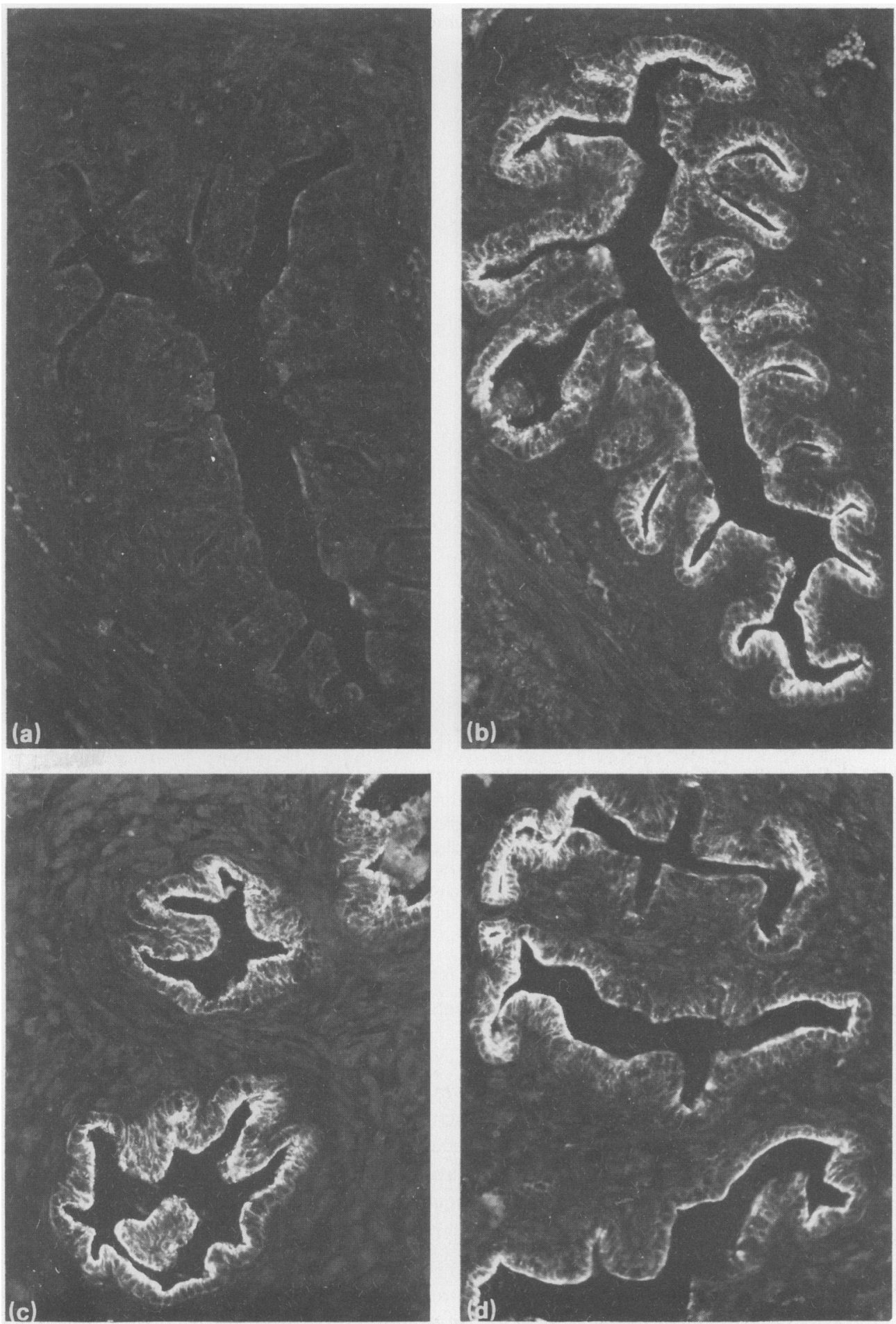

Fig. 5. Fluoresent labelling of se in the exeretory ducts of the coagulating giand (b). dorsolateral prostate (c). and ventral prostate ylands (d). There is labelling at the basolateral borders of the epithedjal cells and heaty labelling in the apical portions of many colls. for the control histological section of an excretory duct of a coagulating gland fal. normal rabhit serum was used in place of anti-se during the labelling procedure. Similar neative results were obtaned when an exeess of purified se wascombined with anti-sc betore labelling the section. a. $\times 210: b$. $\times 180: 2 \times 170: \mathrm{d}, \times 180$. 

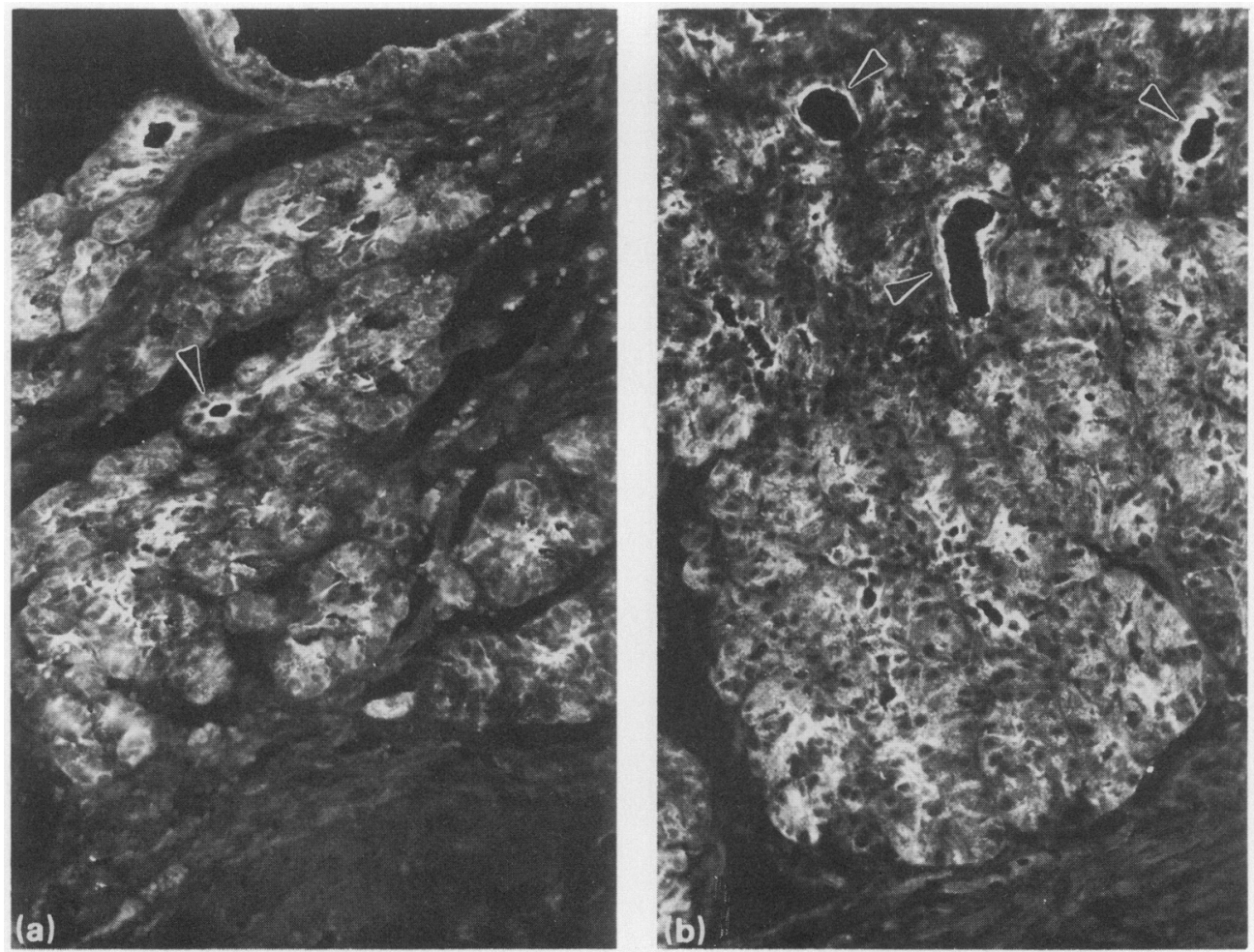

Fig. 6. Labelling of sc in the acini and ducts (arrowhead) of the urethral gland located in the wall of the proximal portion of the pelvic urethra (a) and in the bulbous portion (b). In (a) the epithelial lining of the urethra (top) appears labelled, but closer inspection shows that the label is coating the luminal surfaces of the epithelial cells and is not inside the cells. In (b), there is bright labelling of sc in the acini and ducts (arrowheads) of the urethral gland in the bulbous portion of the urethra. Compare Fig. 6(a) to Fig. 3(b) and Fig. 6(b) to Fig. 4(b). a, $\times 140$; b. $\times 190$.

urethra is a common chamber receiving urine, spermatozoa, and the secretions of the accessory and urethral glands.

Another area of interest in this study is the bulb of the penis. Upon entering the bulb, the urethra gives off a sac-like, bifurcated diverticulum known as the urethral sinus (Fig. 2). The wall of the bulb is richly supplied with compact glandular tissue similar in histological appearance to the urethral gland in the pelvic urethra. Each diverticulum of the urethral sinus is about $45 \mathrm{~mm}$ long, and the glandular tissue in its wall measures about $1 \mathrm{~mm}$ in width at its thickest region. The histological appearance of some of the aforementioned regions of the genital tract is shown in Figs 3 and 4 .

\section{Immunolabelling of sc and $\lg A$ in the rat}

A summary of the localization of sc in the urogenital tract of the male rat is presented in Table 1. There was bright labelling in the excretory ducts of certain accessory glands as they entered the proximal part of the glandular pelvic urethra (Fig. 5) and in the ducts of the urethral gland both in the pelvic and bulbous regions of the urethra (Fig. 6). There was weaker labelling of $s c$ in the epithelial cells of the ventral lobe of the prostate gland. Bright labelling of sc was present along the apical border of the urethral epithelium along its entire length. This labelling appeared to be 
Table 1. Immunohistochemical localization of secretory component in the urogenital tract of the male rat

\begin{tabular}{lc}
\hline Structure & $\begin{array}{c}\text { Secretory } \\
\text { component }\end{array}$ \\
\hline Testis & 0 \\
Epididymis (caput and cauda) & 0 \\
Ductus deferens & 0 \\
Ampullary gland & 0 \\
Seminal vesicle & 0 \\
Coagulating gland & 0 \\
Dorsolateral prostate gland & 0 \\
Ventral prostate gland & 1 \\
Excretory ducts of coagulating & \\
gland & 3 \\
Excretory ducts of ventral & \\
prostate gland & 3 \\
Excretory ducts of dorsolateral & \\
prostate gland & 3 \\
Ejaculatory duct & 3 \\
Acini of urethral gland $\dagger$ & $2-3$ \\
Ducts of urethral gland $\dagger$ & $2-3$ \\
Bulbourethral gland & 0 \\
Preputial gland & 0 \\
Penis & 0 \\
Kidney & 0 \\
Urinary bladder & 0 \\
Urethral epithelium & 0
\end{tabular}

*Brightness of fluorescent labelling, with 0 being none and 3 the brightest.

†Urethral gland in both the pelvic and bulbous parts of the urethra.

coating the luminal surface of the cells rather than being located intracellularly. Labelling of sc was absent in all other tissues examined.

Plasma cells containing IgA were not detected in any of the tissues listed in Table 1, but such cells were observed in the urethral gland in the bulbous part of the urethra outside the urogenital sinus (Fig. 7). Here, IgA-positive cells were present in the glandular stroma at the border of the acini. These labelled cells showed the features of plasma cells when they were stained with haematoxylin and eosin.

\section{Immunolabelling of $\operatorname{Ig} A$ in the mouse}

IgA-containing plasma cells were observed in the urethral gland in the bulbous part of the urethra outside the urogenital sinus in the same location where such cells were observed in the rat. IgA-containing plasma cells were not observed in the testis, epididymis, vas deferens, prostate glands, seminal vesicles, coagulating glands, ampullary glands, penis, or preputial glands. The morphology and localization of IgA plasma cells in other portions of the male mouse urogenital tract were not examined.

\section{Discussion}

This study has demonstrated the occurrence of sc at several sites in the rat male urogenital tract, including the ejaculatory ducts and the urethral glands in the wall of the pelvic and bulbous parts of 


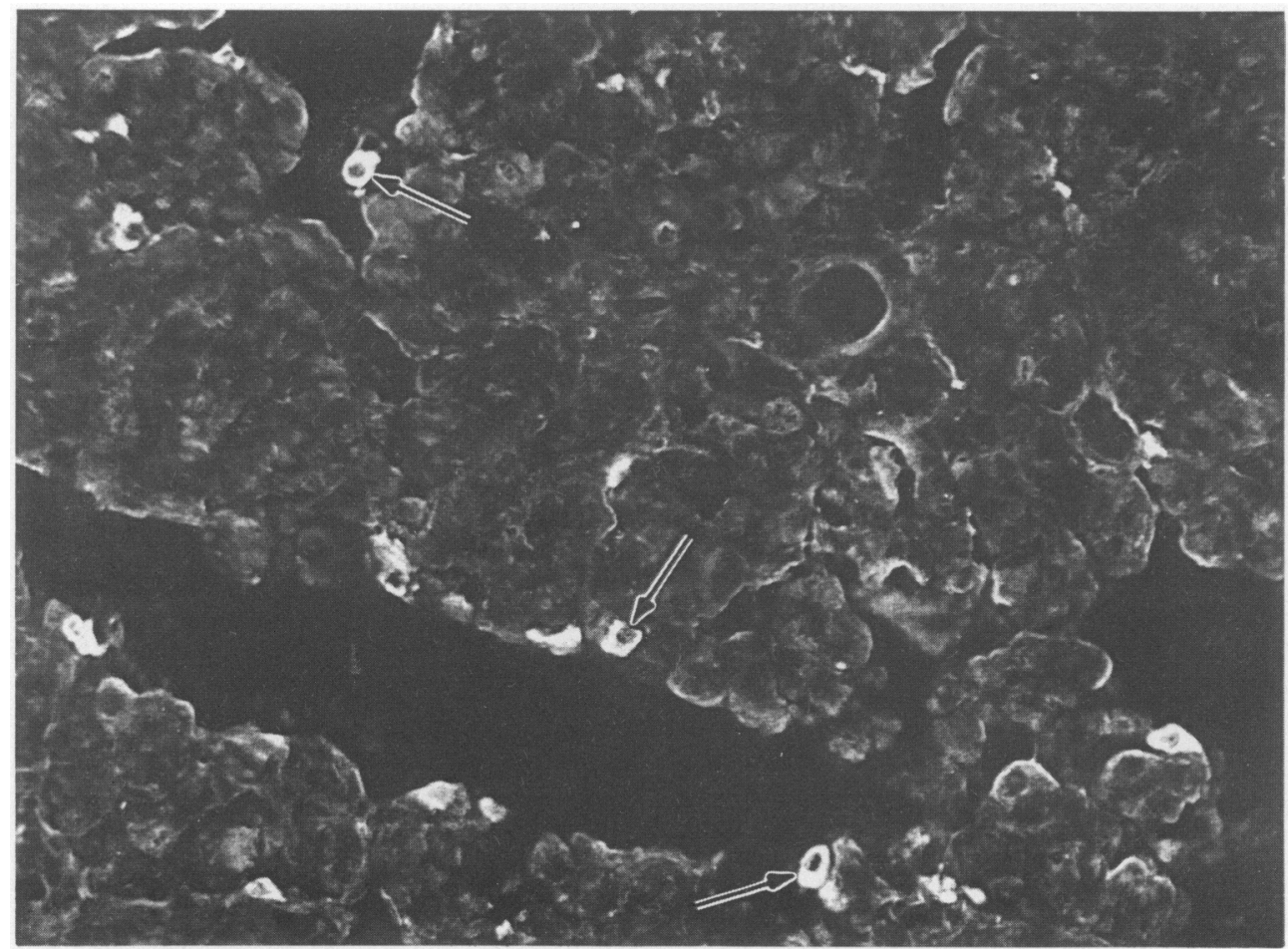

Fig. 7. This photomicrograph shows IgA plasma cells (arrows) at the base of the acini in the urethral gland in the bulbous portion of the rat urethra. Control sections of this tissue showed no labelling of plasma cells. $\times 310$.

the urethra. The receptor for $\lg \mathrm{A}$ was also located in the excretory ducts of the coagulating glands, ventral prostate, and dorsolateral prostate glands near the region where these ducts enter the proximal part of the glandular pelvic urethra. A small amount of sc was detected in the glandular epithelium of the ventral prostate. Plasma cells containing IgA were seen in rats and mice only in the urethral gland in the bulbous part of the urethra at the urogenital sinus. No other structure listed in Table 1 showed any IgA-containing lymphoid cells in either species. The results suggest that $\operatorname{IgA}$ is transported into the rat urogenital tract distal to the sites of production of urine, spermatozoa and seminal fluids. The absence of IgA-containing plasma cells from most of the sites where sc was detected suggests that much of the IgA secreted into the rat male tract may be derived from serum. Serum has been suggested to be the main source of secretory IgA in the human uterus (Tourville et al., 1970; Rebello et al., 1975; Kelly \& Fox, 1979), the genital tract of the female rat (Parr \& Parr, 1989), the dog salivary gland (Montgomery et al., 1977) and the mammary gland during early lactation (mouse: Halsey et al., 1980; sheep: Sheldrake et al., 1984).

The presence of sc or sc and IgA plasma cells in the urethral gland in the pelvic and bulbous urethra, respectively, suggests that IgA may be transported into rat urine at these sites. Human urine contains both IgA and sc (Turner \& Rowe, 1967; Bienenstock \& Tomasi, 1968), but the origins of these proteins in the urine are not known. Urethral glands in the human (glands of Littre) appear to be analogous to the urethral glands in rodents, but it remains to be determined whether they are a site of immunoglobulin transport into human urine. In the female rat sc was detected in the superficial layer of cells in the stratified epithelial lining of the urethra and in associated urethral glands but not in the urinary bladder, ureter or kidney (Parr \& Parr, 1989). In contrast, no se was 
detected in the urethral epithelium of the male rat in the present study. IgA may therefore be transported into urine at different sites in the male and female rat. That urinary IgA may participate in immune defence mechanisms is suggested by the observations of Tourville et al. (1968), who demonstrated naturally occurring $\operatorname{IgA}$ antibodies against $E$. coli in the urine of normal individuals. In immunized individuals, urinary IgA antibodies against $S$. typhii (Turner \& Rowe, 1964), polio virus (Berger et al., 1967) and tetanus toxoid (Turner \& Rowe, 1967) also have been reported. Moreover, urine from children with recurrent bacterial urinary tract infections contains elevated amounts of sIgA (Uehling \& Stiehm, 1971). These observations support the possibility that sIgA in the urinary tract may protect it against infection.

The role of sIgA in seminal fluid is not well understood. Bacteria isolated from prostatic fluid of patients with prostatitis were coated with IgA and IgG antibodies (Drach \& Kohnen, 1977). Uehling (1971) has indicated that sex-associated diseases such as prostatitis and non-specific urethritis may be accompanied by abnormally high local levels of IgA, and has suggested that seminal fluid immunoglobulins may have antibacterial activity in the vagina and may prevent harmful effects of vaginal bacteria on spermatozoa. It is also of interest that seminal fluid spermagglutinating antibodies are mainly of the IgA class (Friberg, 1974) and may be produced locally in the male reproductive tract (Coombs et al., 1973; Husted \& Hjort, 1975; Witkin et al., 1981). The role of sperm antibodies in infertility is of particular importance (Beer \& Neaves, 1978; Bronson et al., 1984). Collectively, these observations suggest that $\operatorname{IgA}$ in seminal fluid and urine may be involved in protecting the urogenital tract against infection and that, in some cases, it may be implicated in human infertility.

We thank Dr Brian J. Underdown (McMaster University, Ontario, Canada) for his generous contribution of purified rat sc, sIgA and anti-rat sc antibody; Shonah Hunter for excellent technical assistance; Shereen Baig and Mark Themig for help in the laboratory; Karen Schmidt for her skilful drawings; and Jeanette Robinson for accurate typing of the manuscript. This work was supported by NIH research grant HD 17337.

\section{References}

Ablin, R.J., Soanes, W.A. \& Gonder, M.J. (1972) ln vivo bound immunoglobulin in the human prostate-their identification and possible significance. Zeit. Immunitaetsforsch. 144, 233-241.

Berger, R., Ainbender, E., Hodes, H.L., Zepp, H.D. \& Hevizy, M.M. (1967) Demonstration of IgA polioantibody in saliva, duoduenal fluid and urine. Nature, Lond. 214, 420-422.

Beer, A.E. \& Neaves, W.B. (1978) Antigenic status of semen from the viewpoints of the female and male. Fert. Steril. 29, 3-22.

Bienenstock, J. \& Tomasi, T.B. (1968) $\gamma$ Secretory A in normal urine. $J$. clin. Invest. 47, 1162-1171.

Bronson, R., Cooper, G., \& Rosenfeld, D. (1984) Sperm antibodies: their role in infertility. Fert. Steril. 42, 171-183.

Chodirker, W.B. \& Tomasi, T.B., Jr. (1963) Gammaglobulins: quantitative relationships in human serum and nonvascular fluids. Science, N.Y. 142, 1080-1081.

Coombs, R.R.A., Rumke, P. \& Edwards, R.G. (1973) Immunoglobulin classes reactive with spermatozoa in the serum and seminal plasma of vasectomized and infertile men. In Immunology of Reproduction, pp. 354-359 Ed. K. Bratanov. Bulgarian Acad. Science, Sofia.
Drach, G.W. \& Kohnen, P.W. (1977) Prostatitis. In Urologic Pathology: The Prostate, pp. 157-170 Ed. M. Tannenbaum. Lea and Febiger, Philadelphia.

Friberg, J. (1974) Immunological studies on human sperm-agglutinating seminal fluid. Acta obstet. gynaecol. scand. 36 (Suppl.), 65-72.

Hall, K. (1936) The structure and development of the urethral sinus in the male white mouse with notes on its occurrence in other rodents. J. Anat. $\mathbf{7 0}$, 413-429.

Halsey, J.F., Johnson, B.H. \& Cebra, J.J. (1980) Transport of immunoglobulins from serum into colostrum. J. exp. Med. 151, 767-772.

Hebel, R. \& Stromberg, M.W. (1986) Anatomy and Embryology of the Laboratory Rat. BioMed Verlag, Worthsee.

Hekman, A. \& Rumke, R. (1976) Seminal antigens and autoimmunity. In Human Semen and Fertility Regulation in Men, pp. 245-257. Ed. E. S. E. Hafez. C. V. Mosby Co., St Louis.

Hermann, W.P. \& Hermann, G. (1969) Immunoelectrophoretic and chromatographic demonstration of IgG, IgA and fragments of $\gamma$ globulin in the human seminal fluid. Int. J. Fertil. 14, 211-215.

Husted, S. \& Hjort, T. (1975) Sperm antibodies in serum and seminal plasma. Int. J. Fertil. 20,97-105. 
Kelly, J.K. \& Fox, H. (1979) The local immunological defence system of the human endometrium. $J$. Reprod. Immunol. 1, 39-45.

Levy, B.J. \& Fair, W.R. (1973) The location of antibacterial activity in the rat prostatic secretions. Invest. Urology 11, 173-177.

Montgomery, P.C., Khaleel, S.A., Goudswaard, J. \& Virella, G. (1977) Selective transport of oligomeric IgA into canine saliva. Immunol. Commun. 6, 633-642.

Parr, M. B. \& Parr, E.L. (1989) Immunohistochemical localization of secretory component and immunoglobulin $\mathrm{A}$ in the genital tract of the female rat. $J$. Reprod. Fert. 85, 105-113.

Rebello, R., Green, F.H.Y. \& Fox, H. (1975) A study of the secretory immune system of the female genital tract. Br. J. Obstet. Gynaecol. 82, 812-816.

Rumke, P. (1974) The origin of immunoglobulins in semen. Clin. exp. Immunol. 17, 287-297.

Sheldrake, R.F., Husband, A.J., Watson, D.L. \& Cripps, A.W. (1984) Selective transport of serum-derived IgA into mucosal secretions. $J$. Immunol. 132, 363-368.

Tauber, P.F., Zaneveld, L.T.D., Propping, D. \& Schumacher, G.F.B. (1975) Components of human split ejaculates. I. Spermatozoa, fructose, immunoglobulin, albumin, lactoferrin, transferrin and other plasma proteins. J. Reprod. Fert. 43, 249-267.

Tourville, D., Bienenstock, J. \& Tomasi, T.B. (1968) Natural antibodies of human serum, saliva and urine reactive with Escherichia coli. Proc. Soc, exp. Biol. Med. 128, 722-727.

Tourville, D.R., Ogra, S.S., Lippes, L. \& Tomasi, T.B. (1970) The human female reproductive tract: immunohistological localization of $\gamma \mathrm{A}, \gamma \mathrm{G}, \gamma \mathrm{M}$, secretory 'piece', and lactoferrin. Am. J. Obstet. Gynecol. 108, 1102-1108.

Turner, M.W. \& Rowe, D.S. (1964) Characterization of human antibodies to Salmonella typhi by gel filtration and antigenic analysis. Immunology 7 , 639-656

Turner, M.W. \& Rowe, D.S. (1967) Antibodies of IgA and IgG class in normal human urine. Immunology 12, 689-699.

Uehling, D.T. (1971) Secretory IgA in seminal plasma. Fert. Steril. 22, 769-773.

Uehling, D.T. \& Stiehm, E.R. (1971) Elevated urinary sIgA in children with urinary tract infection. Pediatrics 47, $40-46$.

Witkin, S.S., Zelikovsky, G., Good, R.A. \& Noorbibik, D.A.Y. (1981) Demonstration of $11 \mathrm{~S}$ IgA antibody to spermatozoa in human seminal fluid. Clin. exp. Immunol. 44, 368-374.

Witkin, S.S., Richards, J.M., Bedford, J.M. \& Zelikovsky, G. (1983) IgA-antibody response to vasectomy. Ann. N.Y. Acad. Sci. 409, 890-891.

Received 13 April 1988 